\title{
COMPETENCIES FOR IMPROVING CONSTRUCTION PERFORMANCE: THEORIES AND PRACTICE FOR DEVELOPING CAPACITY
}

\author{
Hedley SMYTH \\ Construction and Project Management, The Bartlett School of Graduate Studies, University College London, UK. \\ E-mail: h.smyth@ucl.ac.uk
}

\begin{abstract}
The focus on improving construction performance has been narrow in many nations using partnering, leanness and supply chain management. This paper asks three practical construction related questions concerning reinventing the wheel across projects, blame culture and continuity of service. In addressing these practical issues, three theories are engaged: organisational learning, emotional intelligence and relationship management. The solutions are enhanced through applying the concepts and, indeed, there is synergy between the concepts. The solutions require investment for the expected return, the theoretical synergy maximising the benefits from the investment. It is argued that such an approach has as much, if not more chance, to yield improvement in construction. The starting point are issues faced in construction and theory is induced through addressing the problems, rather than starting with concepts applied in other sectors and then trying to squeeze them into the construction context.
\end{abstract}

\section{Keywords}

Blame culture, competencies, emotional intelligence, organisational learning, performance, relationship management, service continuity

\section{INTRODUCTION}

The aim in this paper is to take a fresh look at improving construction performance. Many firms use SWOT analysis as a means to revisit their strategic position (see for example, Johnson and Scholes, 1998). Contractors follow this trend, although there is frequently a focus upon internal factors as external market research data has been neglected. An analysis of strengths can tend to focus on what is done well, rather than those things that yield competitive advantage. Being competent is not the same as being strong in relation to the competition (Hamel and Prahalad, 1994; Barney and Hansen, 1995; Smyth 2000). The premise is that any firm can develop up to three areas of competency that have competitive advantage. This paper explores shaping the future of construction at the level of the firm by asking three significant questions that are raised by contractors and clients:

- How can we avoid 'reinventing the wheel' across projects?

- How can blame be avoided within the culture of the contracting firm?

- How can the client receive continuity of service?

Addressing these three issues has practical application, yet adequate and sustainable solutions require investment that is located in three distinct theoretical areas of management science:

- Organisational learning

- Emotional intelligence

- Relationship management 
Whilst each of these areas warrants detailed attention beyond the scope of this paper concerning the practical questions raised, the purpose here is to demonstrate the benefits of an overall approach based upon competencies. So, in exploring these theoretical areas it will be seen that there are close, indeed potentially, interlocking relationships between these areas, which have a self-reinforcing dynamic that will yield competitive advantage. Out of these theoretical issues, practical outcomes to the three significant questions are provided.

The direction of the argument is to demonstrate that improving construction performance can take a number of paths. There is an underlying assertion that improving construction performance need not be the outcome of primarily pursuing procurement solutions. A great deal of attention has been given to the drive towards improving construction performance through procurement and partnering (see for example, Cox and Townsend, 1998). Partnering has been seen as a procurement tool for reducing costs. In the UK, cost reduction has been manifested through lean construction (Egan, 1998). Whilst current drives towards improvement are being responded to, for example in the UK, it can be argued that more investment is being made by contractors into restructuring the industry than responding to the initial Egan Report (1998) and others in its wake (for example, Fairclough, et al., 2001; Egan, 2002). The practical questions generated in this paper are construction related and the mobilisation of concepts and theory have been induced from the practical problems in construction, rather than deriving agendas from procurement experience in other industries and then trying to make them fit construction. Theoretically, the current agendas fail to recognise that procurement is the other side of the same coin as marketing (Smyth, 2000). Thus many of the drivers have been one-sided, a trap that contractors have fallen for too because of the tendency towards an inward focus, as cited above when addressing SWOT analysis (cf. Smyth, 2000).

Proof is ultimately in the eating. However, there is a danger that current diets are too narrow and in the case of leanness the outcome might be bulimic. That can only be stated as a challenge. The purpose is not to overthrow the procurement paradigm, for those deriving benefit should continue to pursue their path. The purpose here is to set an alternative path for shaping for the future that can be tested upon adoption further down the line. Economic and management theory suggest advantage is to be gained from differentiation, both for the contractor in defining and managing their markets and for clients in receiving services that more closely match their needs (see for example, Barney, 2002). Diversity is to be encouraged. It could also be argued that addressing these three questions could in practice yield more benefits to clients than current policy agendas to improve construction performance. Although the maximum benefit will accrue from repeat business, as it is in partnering, the solutions to these three questions are applicable to a broader range of clients in terms of needs and project size. It could also be argued that the proposed path is one of lower resistance. However, a return in financial terms requires an investment. Therefore application may be best suited to 'core clients'.

While the direction of this particular paper points to outcomes which address three practical questions, these are not the only outcomes, hence taking a fresh look at improving construction performance can take, indeed, should take diverse directions in order to improve service levels to meet different market needs. Strengthening of the sector through capital concentration going hand in hand with investment will build capacity in the sector that is competence based, hence service based (see Smyth, 1999). Competitive advantage in the market can be eroded as competitors emulate best practice. The larger the investment, the larger the risk, but generally the longer the lead time before erosion commences, because the ability to emulate is more constrained. However, emulation provides advantage to those leaders versus the rest of the players, hence leading to greater market share and capital concentration. This is the ultimate test for the future. 


\section{AVOIDING REINVENTING THE WHEEL}

The first of the three questions was stated as:

\section{How can we avoid 'reinventing the wheel' across projects?}

The issue is easy to define. Simply stated, those on site find themselves faced with similar sorts of problems and are not provided with the means to resolve the problem in the most effective way. The source of the problem is usually one of the following:

- Lack of available technology or equipment

- Lack of resources to hire or buy in the equipment

- Lack of support from the head office

- Lack of strategic forethought

- Lack of a adequately considered method statement

- Poor project planning at the front end

Faced with the issue, those on site tend to blame the management. Whilst this is correct in overall terms, the requirements on site need to be fed back to head office. This requires a system for capturing the information. Within each project there is a learning curve to surmount, systematic procedures, such as following ISO 9001:2000, can assist, yet there remain problems across projects. This is essentially a theoretical problem of organisational learning.

Senge (1993) was one of the pioneers of organisational learning. He advocated that the culture and practices of an organisation were so developed that enterprises became learning organisations. This was achieved by harnessing five disciplines. These are:

- Systems thinking

- Shared Vision

- Challenging Mental Models

- Team Learning

- Personal Mastery

Apart from the last element, all were familiar concepts, however, it is the combination that is important. Assuming the other elements are sufficiently in place, the core issue here is systems thinking. Contractors tend to have a large number of proforma and procedures to administer. This is not the same a having a system. A system begins with the thinking and is more than a series of bureaucratic or contractural procedures.

A system has to be developed in a top down approach. Whilst one of the main functions is clearly to steer and control events, it is also present to facilitate practices and changes in practice. Organisational learning has its prime remit as facilitating change. For this issue there is an additional problem compared to those faced in most other enterprises - there is a physical dislocation between the head office and the temporary project team (cf. Cherns and Bryant, 1983). Therefore the system has to be characterised within a two-stage structure, as shown in Figure 1. Learning is transferred from the project as the first stage to the head office and then devolved to other projects from the head office so that the benefit is transferred. That structure is easy to define and some project organisations have already put the structure in place. It is becoming increasingly easy using intranet project management software and database software. 
The more difficult part is managing the process. First, defining the process is important. Step one is for project personnel to be able to capture the information on site and reflect upon their experience, so that the information becomes a knowledge resource from which others can learn. Step two is to transfer the information and learning to the head office. Step three is for those in the head office to extract the generic learning from the project specific learning. This requires experience in judging what is project specific and what may have wider application in solving particular, or indeed a range of, problems. The fourth step is to disseminate the learning to all projects. This may be instantaneous or there may need to be a bank of learning that is held and mobilised in future projects according to observation from the head office or demand from site. Step five involves either assimilating the learning as it is received on site and applying it in the project or having the skill to recognise a problem and ask the head office what historic learning can be applied in the circumstances (see Figure 2).

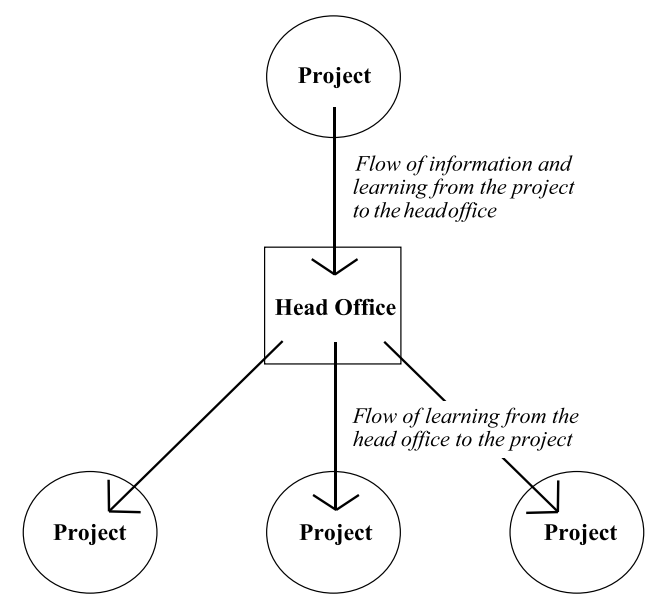

Figure 1: Structure of project organisational learning system

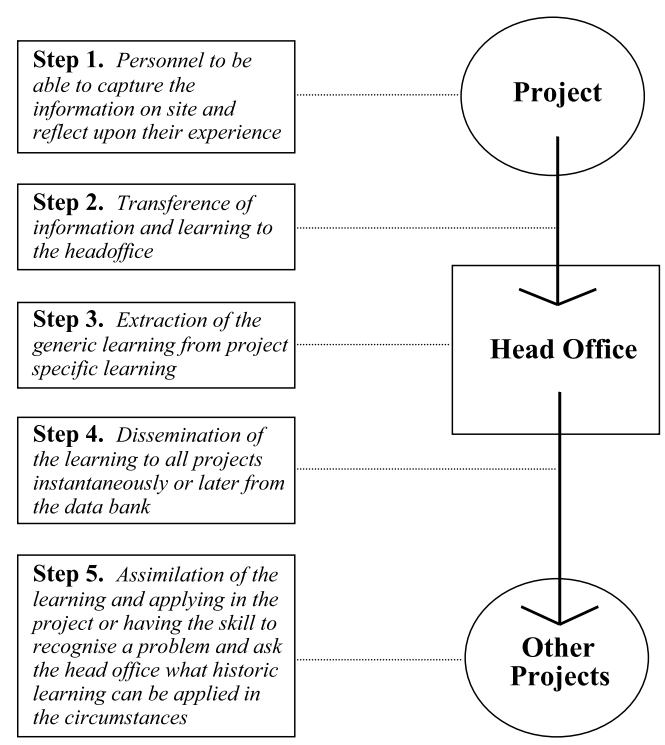

Figure 2: Steps in managing project organisational learning 
It is the process that is difficult to implement for two resource reasons. In the first instant there is no incentive for site personnel to spend any time capturing the information and reflecting upon the experience in order to translate into knowledge from which learning can take place. In fact, the opposite is the case where project cost control is a key in the iron triangle of time-cost-quality. The same applies where the project is in receipt of learning from other projects via the head office. Therefore, a separate resource needs to be made available to project personnel. In addition, a central part of personal development plans and evaluation must be performance in the area of organisational learning and use of the system.

At head office, there must also be a small team with cross-departmental awareness and authority, who can capture the learning and analyse the generic learning for banking and dissemination. They too need a resource to conduct their function and to 'buy in' expertise from the other departments to help evaluate and judge. Some learning will also apply to those departments, such as estimating or for the development of method statements. This too requires a resource for assimilation.

The process is also difficult because it requires not only a physical system to be put in place, but a more general recognition at all levels of the importance of the process and an attitude to adopt the process in both thinking and behaviour. An effective system is the people, the human resource in action. Training in these skills and facilitating cultural change are the keys to success.

The principal of organisational learning is not easy for any organisation to implement. It requires investment backed by commitment. The project environment poses particular problems that make such an investment a higher risk. Yet, because the problem of 'reinventing the wheel' is so pervasive, the benefits of successful implementation are greater: project effectiveness is enhanced, and greater efficiency yielded, which in the long run is translated into net profits once the capital cost has been discounted.

\section{AVOIDING THE BLAME CULTURE}

The second of the three questions was stated as:

How can blame be avoided within the culture of the contracting firm?

There have been improvements in blame reduction between parties through the introduction of new procurement routes, for example design and build and more recently partnering. However, there is the issue of the blame culture within contracting firms. Blame concerns an attitude with attributed behaviour. When that is manifested within an organisation as a general pattern or experience, particularly when facing critical events, then it can be said that the behaviour is embedded in the culture, in this case as a blame culture. Construction is frequently experienced as a blame culture, the quotation below characterising this in terms of the 'street fighting man':

Gangs leaders posture at the street corners vying for a fight. The bully boys always try to get others to do their dirty work for them. Verbal punches hit hard, physical ones are sometimes let loose, but cowardice lurks in the shadows and the heart is filled with fear. The management style of many in contracting 
companies is based upon the street fighting man. Banter and joking, usually at the expense of others, is used for point scoring when things are on a reasonably even keel. If that fails or the pressure is great, verbal abuse and shouting are the weapons to instil fear and maintain power in the office corridor. This is the street corner expression of being special and different. It is an excuse for failing to address the insecurities the individual feels. This is a corporate issue, for a company sets the culture and therefore needs to train and develop those in whom it puts trust and wishes to develop in responsibility. It is an individual issue, for passing the buck and ruling out of fear is ultimately divisive both for the employer and for the individual who is torn apart in managing the conflicts and contradictions of their feelings. The street fighting man knows eventually he will be replaced by someone throwing a harder verbal punch. (Smyth 2000, 12-13).

While the origins and perpetuation of this culture are of importance, the issue in this paper is to pursue a path of avoiding blame, which involves two dimensions:

- Taking responsibility

- Having an outward focus.

Negative behaviour has two negative sources - pride and fear. Blame is essentially pride based. This can be located in Table 1 .

Table 1: Negative cultural corporate behaviour

\begin{tabular}{|l|l|l|l|}
\hline Issues & Behaviour & Embedded Behaviour & Inability to Cope \\
\hline Pride & Performance orientation & $\begin{array}{l}\text { Control and measurement } \\
\text { (incentives and targets) }\end{array}$ & Corporate Paranoia \\
\hline Fear & Blame & $\begin{array}{l}\text { Fight or flight } \\
\text { (essentially defensive) }\end{array}$ & Corporate Hysteria \\
\hline & Shame & $\begin{array}{l}\text { Projecting images and behaviour } \\
\text { (conflict and contradiction) }\end{array}$ & Substantive Inertia \\
\hline
\end{tabular}

Source: adapted and developed from McGee 1998.

Spooncer (1992) has illustrates how behaviour works out in practice (see Figure 3).

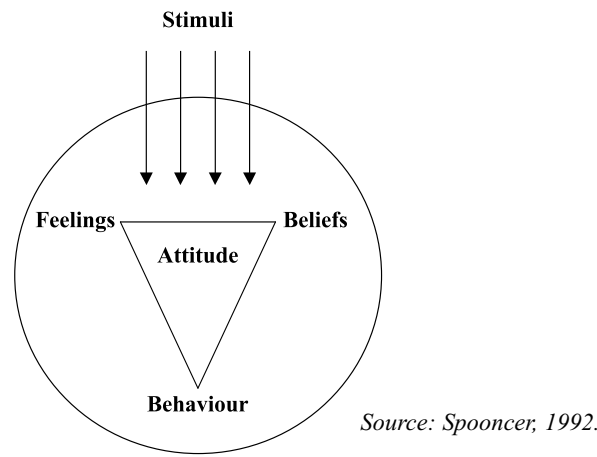

Figure 3: Causal pattern for generating behaviour 
Current circumstantial events and situations act as external stimuli. Beliefs and emotions are mobilised that appear appropriate. Some will accord with the circumstances, while some will 'press buttons', in other words tap back to personal history. This will invoke beliefs, especially expectations as to what might now happen based upon past experience. In turn feelings are invoked, especially embedded ones that have become common responses for the individual, whether these are rationally appropriate or not (Sandford and Sandford, 1982). A parallel process occurs corporately whether behavioural responses are negotiated at a cultural level. This is because most organisations tend to select personnel in their own mould in order that they fit in. The individual tends to seek enterprises into which they will fit as well. The response, whilst not exactly conditioned in any sense of determinism, is strongly influenced and hence is easily negotiated to solicit behaviour to fit the circumstances. In decision making this has been called a mobilisation of bias through decision making and non-decision making (Bachrach and Baratz, 1970). This behavioural process is replicated in a broader context of culture (see for example, Handy, 1993; Hofstede, 1997).

The corresponding positive behaviour to pride and fear arises from confidence and humility. Sometimes it is difficult to deduce the difference between specific positive and negative behaviour in practice because the source is attitudinal motivation. However, a pattern brings forth certain types of outcome, which are discernible.

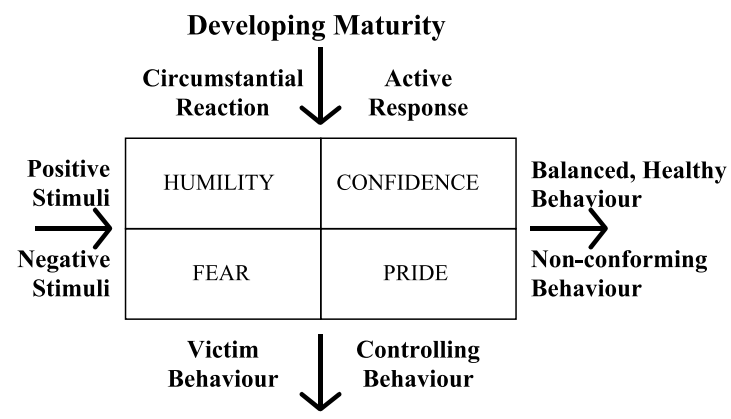

Figure 4: Dynamics of positive and negative behaviour

What the individual can control is the circumstantial reaction and the active response. This is a function of maturity in the sense of resolving those issues that have resulted in others 'pressing buttons'. This also applies at a corporate level. The managerial function is to encourage positive forms of behaviour. It is here that the concept of emotional intelligence is useful (Goleman, 1996; 1998). Goleman argues:

- Emotional intelligence can be broadly defined as the ability to understand:

- Our own emotions

- Feelings of others

- Enhancing learning can increase our IQ by only 7-10\%

- Harnessing our emotional intelligence can affect the success of the individual by $50 \%$.

The process is summarised as:

- Recognising own emotions

- Controlling emotions

- Recognising emotions in others

- Recognising motivations from emotions

- Maintaining emotional links

- Harnessing emotions in creative thinking 
Goleman argues that emotional intelligence is very relevant in group work where specific tasks have been allocated to the group. Druskat and Wolff (2001) has taken this further in a group context. Groups can work more effectively together if they harness emotional intelligence (see Table 2).

Table 2: Process for improving emotional intelligence individually and in groups

\begin{tabular}{|l|l|}
\hline Individual & Team or Group \\
\hline Self-awareness & Group emotional intelligence \\
\hline Regulation & Build trust, identity, efficacy \\
\hline Behaviour & Participation, co-operation, collaboration \\
\hline Personal competence & $\begin{array}{l}\text { Better decisions, creative solutions, higher productivity, } \\
\text { i.e. Group competence }\end{array}$ \\
\hline
\end{tabular}

Source: Druskat and Wolff 2001

This has an inward and outward focus in the sense of seeing situations through the eyes of others. This is beneficial within the enterprise, yet also has benefits when applied at the contractor-client interface. However, the first step is to apply emotional intelligence to the project working environment. Whilst it is beyond the realm of this paper to explore the theory fully, Table 3 provides an indication of the key issues.

However, high performers in groups tend to perform well because they make use of a wider network outside their immediate group or team and call upon the resources in the network to overcome obstacles and aid with problem solving. These informal networks are useful because they are frequently free of the protocols determining group work. Therefore they make two external inputs:

- Knowledge derived from information and expertise

- An ability to think and act "outside of the box".

They offer one more important aspect. It has been pointed out that a group or team may work well together on a day-to-day basis in many ways, but that does not necessarily mean they trust each other. This can inhibit determining productive solutions. However, informal networks tend to fall into three categories:

- Communication webs

- Expertise networks

- Trust networks

Effective workers tend to have dense networks in all three categories (Goleman, 1996). This is part of the individual using their emotional intelligence to overcome internal shortcomings of emotional intelligence within a group setting. This is not to say such groups are dysfunctional, indeed, they can work harmoniously and exhibit trusting behaviour in general, but not always in specific ways or with specific people. 
Table 3: Managing emotions, using emotional intelligence, in teams

\begin{tabular}{|c|c|c|c|}
\hline Norms & Individual & Group & Cross-boundary \\
\hline $\begin{array}{l}\text { Norms that } \\
\text { create } \\
\text { awareness of } \\
\text { emotions }\end{array}$ & $\begin{array}{l}\text { A. Interpersonal } \\
\text { Understanding } \\
\text { Take time away from work } \\
\text { to get to know each other } \\
\text { "How's it going"; informal } \\
\text { pre-ambles before each } \\
\text { meeting } \\
\text { Undesirable behaviour has } \\
\text { a root, so find out } \\
\text { Tell others how you're } \\
\text { feeling, what you're } \\
\text { thinking } \\
\text { B. Perspective Taking } \\
\text { Ask if all agree with a } \\
\text { decision } \\
\text { Ask quiet members what } \\
\text { they think } \\
\text { Question quick decisions } \\
\text { Appoint a provocateur }\end{array}$ & $\begin{array}{l}\text { A. Team Self-evaluation } \\
\text { Schedule time to examine team } \\
\text { effectiveness } \\
\text { Create measurable tasks and } \\
\text { process objectives and measure } \\
\text { them } \\
\text { Acknowledge and discuss group } \\
\text { moods } \\
\text { Communicate your sense of what } \\
\text { is transpiring in the team } \\
\text { Allow people to call a process } \\
\text { check, e.g. is this the most } \\
\text { effective use of our/your time? } \\
\text { B. Seek Feedback }\end{array}$ & $\begin{array}{l}\text { A. Organisational } \\
\text { Understanding } \\
\text { Find out needs and } \\
\text { concerns of others in the } \\
\text { team/organisation } \\
\text { Who outside the team can } \\
\text { positively influence progress } \\
\text { Discuss organisational } \\
\text { culture and politics } \\
\text { Are team actions congruent } \\
\text { with organisational culture } \\
\text { and politics? }\end{array}$ \\
\hline $\begin{array}{l}\text { Norms that } \\
\text { help regulate } \\
\text { emotions }\end{array}$ & $\begin{array}{l}\text { A. Confronting } \\
\text { Set ground rules and use } \\
\text { them to point out errant } \\
\text { behaviour } \\
\text { Call members accountable } \\
\text { on errant behaviour } \\
\text { Create playful ways to } \\
\text { point out errant behaviour } \\
\text { B. Caring } \\
\text { Support members } \\
\text { Validate member's } \\
\text { contributions } \\
\text { Protect members from } \\
\text { attack } \\
\text { Respect and listen to } \\
\text { differences } \\
\text { Don't be derogatory or } \\
\text { demeaning }\end{array}$ & $\begin{array}{l}\text { A. Creating Resources for } \\
\text { Working with Emotions } \\
\text { Make time to discuss difficult } \\
\text { issues and emotions } \\
\text { Find appropriate ways to express } \\
\text { and acknowledge emotions in } \\
\text { short hand way } \\
\text { Create fun ways to acknowledge } \\
\text { and relieve stress } \\
\text { Express acceptance of members } \\
\text { and therefore their emotions } \\
\text { B. Creating an Affirmative } \\
\text { Environment } \\
\text { Reinforce a team's capacity to } \\
\text { respond to challenges } \\
\text { Focus on what you can control } \\
\text { Remind members of the mission } \\
\text { Remind members of past successes } \\
\text { Focus on solving, not blaming } \\
\text { C. Solving Problems Practically } \\
\text { Take preventative action } \\
\text { Take initiative to understand and } \\
\text { secure resources } \\
\text { Do it yourself if others won't }\end{array}$ & $\begin{array}{l}\text { A. Building External } \\
\quad \text { Relationships } \\
\text { Create networking and } \\
\text { interaction opportunities } \\
\text { Ask about needs of other } \\
\text { teams } \\
\text { Provide support for other } \\
\text { teams } \\
\text { Invite other teams to send } \\
\text { members to meetings if } \\
\text { they may have a stake in the } \\
\text { outcome }\end{array}$ \\
\hline
\end{tabular}


It is unnecessary to explore this further, the point being that harnessing emotional intelligence generally, and specifically in a group or team context, facilitates an outward focus in a healthy way rather than one that blames others in order to protect or defend one's own territory. This process has to be supported by senior management. It is not a process that can be initiated and developed very far from a bottom-up mode of operation. It has to be demonstrated as well as advocated from the top down. There must also be a resource to facilitate the process and this has programming implications for the project. Avoiding the blame culture therefore has a cost to it. It also is an anathema to many current organisations, so the investment will be reasonably substantial over the longer term to facilitate the change. However, the level of differentiation in service can be considerable and is likely to be more effective. It will be more effective in creating a more rewarding and satisfying working environment. It will be more effective in taking responsibility and resolving project and client issues, which will yield a return on the investment.

There is clearly a link between the first question concerning avoidance of reinventing the wheel and this question on avoidance of the blame culture. The link is a conceptual one within the theory of organisational learning. Senge (1993) incorporated personal mastery into his five elements for developing the learning organisation. This was a new area grafted onto the four others and drawn together to form an integrated approach. Emotional intelligence can be viewed as a facet of personal mastery and developed in a team context also links with team learning. Figure 5 shows how the theory is linked.

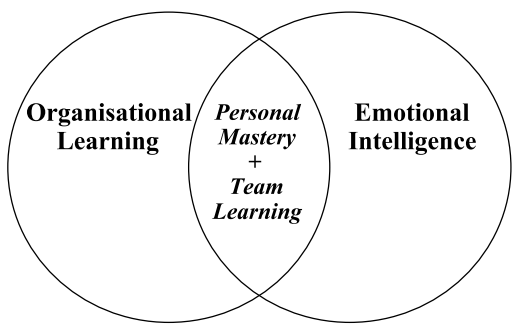

Figure 5: Conceptual links in avoiding a blame culture

\section{RECEIVING CONTINUITY OF SERVICE}

The third of the three questions was stated as:

\section{How can the client receive continuity of service?}

A common experience of many clients is that they fail to receive a continuity of service. At the crudest level this occurs because 'Team A' is put forward to win the bid and even if this team commences the project, the team is then withdrawn to secure the next contract for the contractor and hence 'Team B' is brought onto the project, and so on until hand-over is being carried out by a team led by an older, probably 'less dynamic' yet experienced site manager. There is nothing wrong with this approach per se, however, the usual experience is that each team is given little or no briefing from the previous one. There is little knowledge transferred about the:

- Client expectations and needs

- Essential project history

- Specific project issues and problems for resolution 
The result is a lack of service continuity. This is important beyond an anecdotal level for market research has demonstrated that the client is typically impacted $80 \%$ by the service and $20 \%$ by the project, the exact reverse of contractor perceptions of their function (Leading Edge, 1998). A service gap therefore opens up.

There are two options to this question:

- Account handler

- Relay team

The account handler model comes from the world of advertising agencies. This is the person responsible for that whole account, including all the projects within the account. It is a hands-on role. It involves both supervisory and day-to-day management. The account handler is responsible for getting under the skin of the client at a detailed level. The account handler may even ask to attend the client's own 'in-house' meetings on occasions. The account handler can be a contracts director, business development manager or a member of senior management. They are involved from initial contacts, through tendering, work on site and beyond the final account in order to maintain contact for repeat business purposes. This achieves continuity of service (Smyth, 2000).

The relay team is the model where the contractor does not keep the same continuity of staff. Changes between sales and the contract staff, off site managers and so on are all acceptable. What is different is that there is a comprehensive and detailed understanding transferred. Unlike a relay race among young school children where there is no baton, the person on the first leg having to touch the hand of the person running the second leg, except they run out of steam and the second leg runs ahead of time anyway. That is a picture of the primary hand-over on projects, whereas, in the relay team approach the transfer is represented by the baton. If you drop the baton you are disqualified. Therefore transfer concerns knowledge of the following:

- Specific offer and promises made to the client

- Expectations of the client

- What actions are being taken to satisfy the client and the project tasks

- What approach informs those actions - this understanding and practical approach is like the baton that is transferred between the relay team members at each leg of the race.

The important point here is that in advance the client knows:

- What personnel changes are going to be made.

- When those changes are going to be made.

For example, in advance of the contract starting on site the client will be aware that the site manager will change half way through the project. The first manager has strengths at initiating a project, galvanising the team and can take a strong role in co-ordinating the overall progress.

The manager for the second half pays attention to detail, is better at completing and finishing tasks and will mobilise resources to provide a good quality finish. Therefore while it benefits the contractor to pull off the first site manager to secure and start new projects, there are benefits for the client, which are also made quite clear. This can be fine, providing this communication actually happens, those strengths are apparent and the baton of understanding 
and service is passed between the contracting staff. At the end of the project, the baton is handed back to the sales staff to court for repeat business (Smyth, 2000).

In both models, continuity is managed and maintained. The former is probably marginally better for the client, but provides least flexibility for the contractor. The choice is a strategic one, but its implementation is a marketing and resources matter. There may be different choices adopted for core and non-core clients. Core clients will probably include those where strategic partnering, framework agreements, BOOT and other long-term alliances are involved.

While the relay team approach addresses continuity within a project, it does not address continuity across projects. Where there are long standing clients, who are core clients, a continuity of service is important across projects and the account handler is more appropriate. Continuity of information and approach are also important ways of achieving continuity. However, clients are well aware of circumstances where the experience on one project is not replicated on another. Yet when a consumer buys a Mars bar or goes to McDonalds they expect the same product or service. McDonalds may not be the best food in the world, although some children may disagree, but that is not why you go. It is because you know what you are getting whether it is in Birmingham, Budapest or Beijing. The same is not true of contracting. Whilst every 'product' is unique, there is no reason why the service should be. The main reason the service varies is related to the blame culture associated with the second question. A blame culture promotes defensiveness, isolation and individualism to unhealthy levels. One joke about the construction industry is, 'Construction is the most conservative industry, run by anarchists'. One aspect of the blame culture or a sub-division of it is a personality-based culture at the site level. The experience of the client on a project largely depends upon the personality and style of the site manager and their contracts director too, who mediate their skill, abilities and management through their personality. The account handler system does not necessarily overcome this dimension.

What is needed is a system between the head office and the project that regulates the type of service received by the client. This should not stifle the personalities, nor skills of those concerned, but act as an essential framework that guarantees a minimum common experience for the client, which is then enhanced by personal attributes. The kind of service delivered through such a system has the potential to differentiate the service of one contractor compared to another according to the market segments served. This will yield competitive advantage in those segments and aid market management in a proactive way (Smyth, 2000). This is not to say that service experiences will become as uniform as McDonalds - far from it, but there is a long way to go to improve service continuity across contracts for clients.

This begs the question as to what sort of system. Contractors are already weighed down with proforma and procedures. These are not the same as a system. It has been stated that a system commences with thinking. Indeed, it need not even be paper or computer based. Service continuity is essentially a human experience, therefore, it makes sense to make the system relationship based. This will also enhance continuity at a project level, especially where the account handling approach is used.

As many of the drivers for improving construction performance have come from the client and are thus essentially procurement based. It is logical to address this issue from the other side of the same coin, that is, marketing and specifically relationship marketing. Indeed, relationship marketing has developed into a management approach in much the same way 
that procurement theories of leverage have developed lean production and supply chain management concepts.

Storbacka, et al., (1994) have provided a systematic framework for managing relationships (Figure 6).

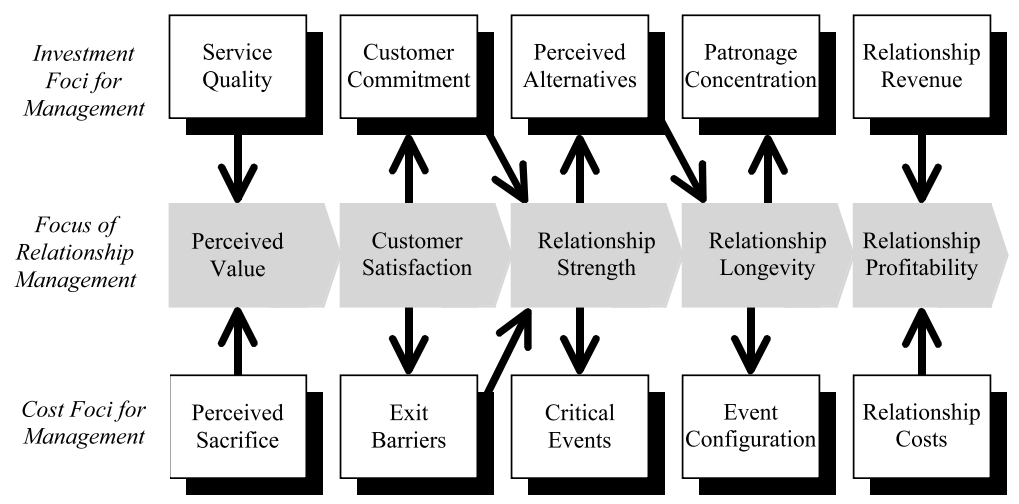

Figure 6: Model of relationship management Source: adapted from Storbaka et al., 1994; see also Gummesson, 1999 and Smyth, 2000.

The central line is the focus for management, the aim being to translate the value instilled in the product and service into a premium profit by virtue of the delivery of the service in a way that yields high satisfaction levels. Satisfaction is derived in this case from continuity, although there are other areas to pursue. This does not happen in an automatic or mechanical way (cf. the marketing mix or transaction marketing). The top line focuses upon the head office investment necessary to ensure the added service value, while the lower line shows the likely costs that are to be incurred as issues arise in practice and must be overcome to avoid weakening or rupturing the service value.

This model is applicable to all enterprises in general terms. However, in a project environment a supplementary model is needed to interface between managing the client enterprise and their project or projects. This is shown in Figure 7. This project model is not a substitute for the primary model but works underneath it.

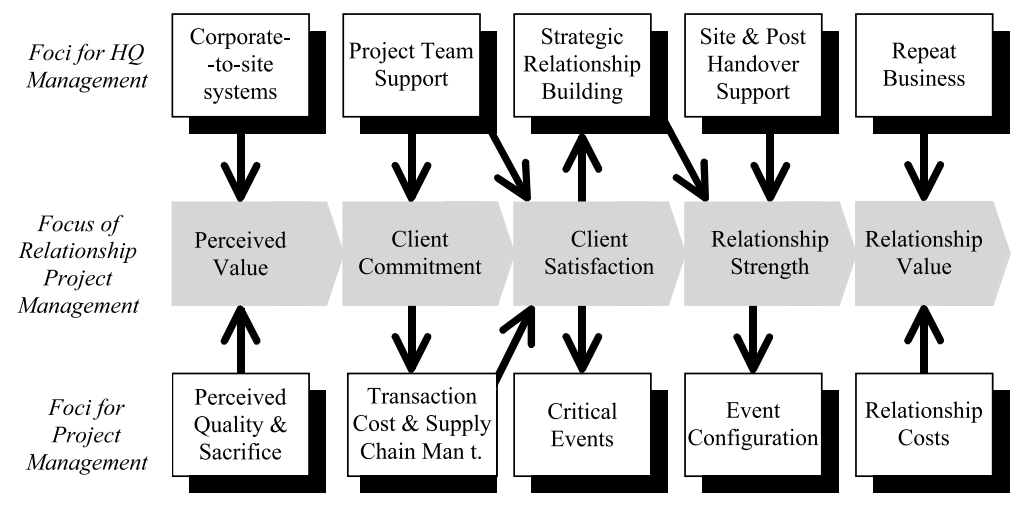

Figure 7: Model of relationship management of projects 
These two models need to be linked in investment terms as relationship management is not a low cost activity, requiring investment in advance and continual enhancement of the service as others in the market emulate, hence erode, competitive advantage. This is shown in Figure 8. This figure shows more about the dynamics, hence actions that are necessary to pursue the relationship management option in a coherent way. It should be noted that the 'project' is therefore redefined in terms of the length of the relationship, hence where there are a series of projects, and repeat business is one of the main justifications for this approach, then a programme of projects is a more realistic focus.

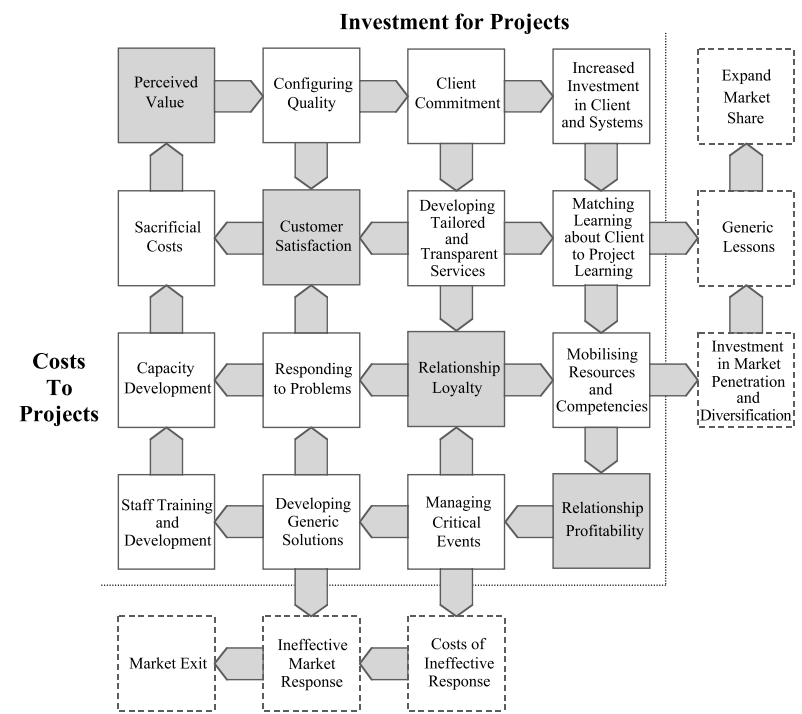

Figure 8: The investment and cost dynamics of relationship management for project working

It is this type of investment and cost activity that will yield a service that has continuity across projects, from which clients will build up a picture of consistency in approach by both direct experience and reputation in the market.

At the level of the individual project there is a link to emotional intelligence. This is in evidence in the sense that the personality basis of operation is replaced by, either the account handler, or a relay team with a baton, which permits management to provide continuity and to employ emotional intelligence. There is also a link to organisational learning for two reasons. The first reason is that a system is being put in place through relationship management for the enterprise as well as the project. This can provide an excellent conduit for learning organisational principles to be enacted (see Figure 9).

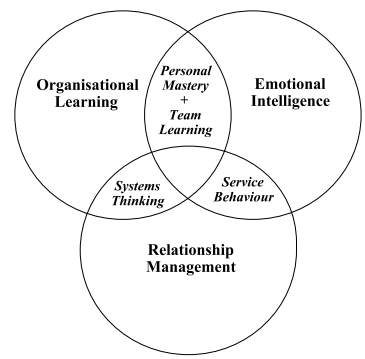

Figure 9: Conceptual links in avoiding a blame culture 


\section{CONCLUSION}

The paper has shown that the three questions concerning reinventing the wheel, blame and consistency can be addressed. They have been addressed both practically and theoretically. Addressing these questions requires investment to yield a result. The theoretical exposition shows that there are links between the areas. This means that the investment is synergistic, where the same investment can help address more than one question.

The paper has been an implicit critique of the thinking confined to improvement through partnering, lean construction and supply chain management. Indeed, it is also argued that these other agendas are derived from procurement experience in other industries, whereas the questions generated here have been construction related and the mobilisation of concepts and theory has been induced from the practical problems in construction, rather than trying to shoehorn other concepts into a construction setting. However, the approaches are not mutually exclusive and can be applied to supplement and complement the procurement led approach.

The likelihood of success in shaping the future of construction has to be borne out in practice and empirically tested, however, the construction related nature of the approach could prove to have greater application, hence yield greater improvement in the long run.

\section{BIBLIOGRAPHY}

Bachrach and Baratz. (1970). Power and Poverty, OUP, Oxford.

Barney, J. B. (2002). Gaining and sustaining competitive advantage, Pearson, New Jersey.

Barney, J. B. and Hansen, M. (1995). "Trustworthiness as a Source of Competitive Advantage", Paper given at the Australian Graduate School of Management, University of South Wales, Sydney.

Bontis, N. (1998). "Intellectual Capital: An Exploratory Study that Develops and Models", Management Decision, 36(2), 63-76.

Cherns, A. B. and Bryant, D. T. (1983). "Studying the Client's Role in Construction Management", Construction Management and Economics, 1, 177-184.

Cox, A. and Townsend, M. (1998). Strategic procurement in construction, Thomas Telford, London.

Dawson, R. (2000). Developing knowledge-based client relationships: The future of professional services, Butterworth-Heinemann, Oxford.

Druskat, V. U. and Wolff, S. B. (2001). "Building the Emotional Intelligence of Groups", Harvard Business Review, March, 81-90.

Edvinsson, L. (2000). "Some Perspectives on Intangibles and Intellectual Capital”, Journal of Intellectual Capital, 1(1), 12-16.

Egan, Sir John. (2002). Accelerating change, [online]. Available at: http://www.dti.gov. uk/construction Fairclough, Sir John et al. (2001). Rethinking construction, innovation and research, HMSO, London. Goleman, D. (1996). Emotional intelligence, Bloomsbury, London.

Goleman, D. (1998). Working with emotional intelligence, Bloomsbury, London.

Gronroos, C. (2000). Service management and marketing, John Wiley and Sons, London.

Gummesson, E. (1999). Total relationship marketing, Butterworth-Heinemann, Oxford.

Hamel, G. and Prahalad, C.K. (1994). Competing for the future, Harvard Business Books, Boston, MA. Handy, C. (1993). Understanding organisations, $4^{\text {th }}$ Ed., Penguin, Harmondsworth.

Hofstede, G. (1997). Cultures and organisation: Software of the mind, McGraw-Hill, London.

Johnson, G and Scholes, K. (1998). Exploring corporate strategy, Prentice Hall, London.

Leading Edge (1998). On the edge, 9.1, Leading Edge Management Consultancy, Hitchin. 
McGee, R. S. (1998). The search for significance, Word Publishing, Nashville.

Sandford, J. and Sandford, P. (1982). Transformation of the inner man, Victory House, Tulsa.

Senge, P. (1993). The fifth discipline, Random House, London.

Smyth, H.J. (1999). "Performance Audits and Client Satisfaction", Proceedings of the CIB Symposium on Customer Satisfaction, September, Cape Town.

Smyth, H. J. (2000). Marketing and selling construction services, Blackwell Science, Oxford.

Spooncer, F. (1992). Behavioural studies for marketing and business, Stanley Thomas, Leckhampton.

Storbacka, K., Strandvik, T. and Gronroos, C. (1994). "Managing Customer Relationships for Profit:

The Dynamics of Relationship Quality", International Journal of Service Industry Management, (5)

5, 21-38. 